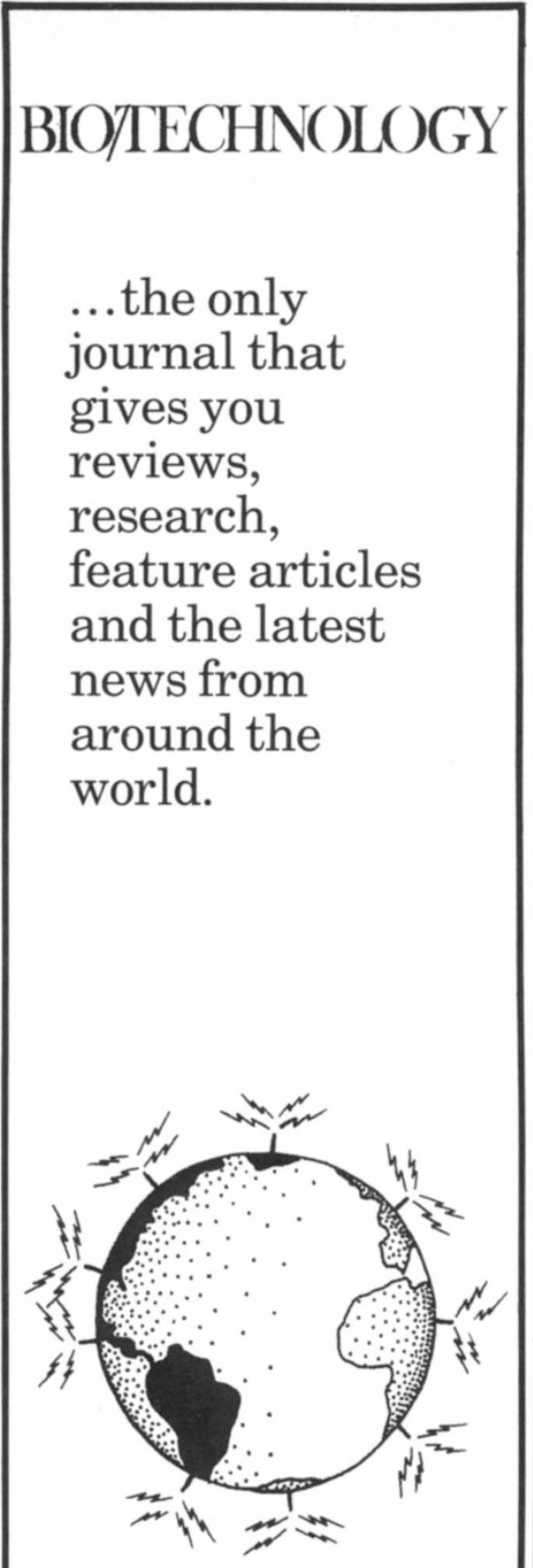

\title{
COMMENTARY/
}

\section{SOLUBLE CD4: DO THE MEANS JUSTIFY THE ENDS?}

The beginning of the year witnessed a spate of papers showing that a 1 soluble form of the CD4 receptor protein could neutralize the in vitro infectivity of the AIDS-related virus (HIV). With those publications, three United States pharmaceutical companies-Genentech, Biogen and Smith Kline \& French-officially entered into competition for the commercial development of this molecule. Their papers clearly indicated they were all working with the parent DNA sequence reported from Richard Axel's laboratory at Columbia University (Maddon et al. Cell 42:93, 1985). But, according to a figure legend in a letter appearing in the Bastille Day number of Nature (Bedinger et al. 334:162, 1988), this sequence is incorrect. The following is an attempt to sort out the resulting confusion.

In the Cell paper, Axel's group deduced an amino acid sequence of the mature protein from a cDNA clone obtained by Dan Littman (now at Howard Hughes Medical Institute). They predicted an asparagine (asn) at the +3 position. But a few days ago, Littman told us the amino end of the processed protein actually contains lysine (lys) at the asn assignment. Additionally, the lys is not at +3 but rather at the $N$-terminus. Resequencing revealed what had happened: a single base had been misread. Instead of the actual AAG codon, the paper submitted to Cell reported an $\mathrm{AAC}$, and the leader-sequence cleavage site was displaced by two amino acids. This is the error that Littman's lab corrected in the figure legend (Bedinger et al., op. cit.).

Ironically, the Biogen group discovered this discrepancy when they sequenced their own cDNA, but attributed it to a possible polymorphism and chemically changed the AAG to an AAC to 'agree with the previously published sequence'(Fisher et al. Nature 331:76, 1988). [Littman (per. comm.) has meanwhile sequenced the genomic DNA for CD4 and finds an AAG (lys) codon, so there seems little doubt now about the real amino end of the human molecule.] Is Biogen therefore expressing and purifying the incorrectly terminated protein? When asked about the molecule Biogen is developing for clinical trials, David Konys (program director for HIV research), acknowledged the faux pas in the Nature paper, but he declined to say whether the current Biogen protein begins with asn or lys. What about the clones the other players in this serious game are using?

Martin Rosenberg, vice president for research and development at Smith Kline, told us their soluble CD4, which is derived from the Columbia group's DNA, begins with a lysine. He said they discovered the disparate sequence when they obtained the clone, but saw no compelling reason to raise the point in their paper in the CD4 issue of Nature (Deen et al. 331:82, 1988).

Genentech's CEO, David Martin, would not disclose the N-terminus of his company's protein, which went into Phase I human trials in August. He did say, however, that "At the time of the Biogen and Smith Kline publications, we recognized the Axel sequence was in error." Yet the Genentech paper, which appeared a few weeks earlier (Smith et al. Science 238:1704, 1987), also perpetuates the notion that the Columbia group's sequence is correct. Moreover, at the August symposium of the Protein Society, Genentech scientists presented a paper that says in part, "The actual N-terminus of CD4 corresponds to the third residue of the sequence predicted by Maddon et al. [asn]" (Harris et al. Abst. S153).

Does this mean Sam Broder, at the NCI, is injecting people with an incorrectly terminated protein? If Genentech knew, as Martin says, what the correct N-terminus was, why would it apply to the FDA for permission to test a different molecule? And does it make any difference? After all, preclinical trials are designed to discover any unforeseen toxicity, and most proteins have allelic variants in any case. But curiously, the N-terminus of CD 4 turns out to be highly conserved. The rat, mouse and sheep receptors all begin with lysine (Clark et al. PNAS 84:1649, 1987), as does the human molecule.

We are ignorant enough of the consequences of administering a soluble form of CD4. Let's not fool with the ends when we certainly have the means to get them right.

- Harvey Bialy 